\title{
Sustainability and Conserved Energy Value of Heritage Buildings
}

\author{
Associate Prof. Dalia A. Elsorady \\ Department of Architecture, Pharos University, P.O. Box 37, Sidi Gaber, 21311, Alexandria, Egypt. \\ dsorady@gmail.com
}

\begin{abstract}
Conservation and sustainability have long shared fundamental goals. Heritage buildings are basically sustainable and will continue to be if their sound construction and superior materials are conserved properly. Despite this fact, heritage buildings have gained a reputation for being inefficient and therefore unsustainable in the face of modern, energy-efficient structures. As a result, models which are measured embodied energy arose to advocate the retention of heritage structures over new constructions. The initial need to measure energy capital in buildings started due to rising needs to save energy and address global sustainability goals. Both responses measure overall energy efficiency of heritage buildings by attempting to account for the "energy capital." The life cycle assessment/avoided-impacts model is another model that acts as a response to the evolving metrics and currency of sustainability. The Conservation Green Lab has further developed the capabilities of the life cycle assessment/ avoided impacts model in 2012 in its innovative report: "The Greenest Building: Quantifying the Environmental Value of Building Reuse". With this aim, the study applies energy software models supported by guidelines laid out by LEED, and are consistent with judicious conservation practice on a case study heritage building in Alexandria. The outcome revealed proves that heritage buildings can be both sustainable and energy efficient while maintaining their historic integrity, when dealt with properly.
\end{abstract}

Keywords - Sustainability, Embodied energy, Heritage Conservation, LEED, Life Cycle Assessment, Energy value.

\section{INTRODUCTION}

Heritage conservation has evolved from the aspiration to preserve sites linked to specific identities. The conservation field has also responded to a raise in energy prices, and deficiency of energy 104 sources with a number of initiatives. These initiatives have laid the basis for the embodied energy dispute of the preservation of existing buildings with their locked-up energy rather than substitution with new more energy efficient buildings. Nevertheless, traditionally, sustainability, when dealing with the built environment, has relied heavily on "green technology" and new high performance construction in contrast with conservation projects. The arguments for retention of heritage buildings from an energy value perspective have evolved around the focus of the energy capital embodied within constructions. Additionally, the environmental avoided impacts approach looks at the environmental impacts that are avoided by rehabilitating an existing heritage structure compared to demolition and novel construction.

Continually, the conservation field is faced with the challenge of bridging the gap between operational energy and embodied energy when comparing the efficiency of energy in historic versus new buildings. Operational energy is defined as the energy used within a building to heat, cool and illuminate, as it operates over a typical meteorological year. Operating energy is a vital component when measuring the energy used up in a building; the ability to integrate and mature the operating energy component into the assessment of the "energy capital" of a building will develop the argument for the conservation field. The embodied energy format measured "energy capital" by what had been invested, while the life cycle assessment/avoided impacts scheme measures "energy capital" by what is required to be spent in the future to improve operating efficiency of an existing building [1]. In both cases the "energy capital" of the heritage building is compared to the "energy capital" of a new building.

The methodology of this research consists of an outline of the relationship between sustainability and 
conservation; an in-depth evaluation of the embodied energy model and the life cycle assessment/avoided impacts model, followed by the examination of a case study. Utilization of models is explained and explores potential options for the conservation field to proceed, and to continue to be relevant rather than to indicate these past claims and advances. Embodied energy for the case study building was assessed using the survey method. Environmental consequences, or the avoided impacts, were measured as well as using the Athena Eco-Calculator provided by the Athena Sustainable Materials Institute in Canada. The investigation of a case study was used to draw conclusions about how to better lever conversation sustainability, specifically as those conclusions relate to energy value in heritage structures.

\section{LITERATURE REVIEW}

\section{A. Conservation, Sustainability and Energy}

Sustainable development is defined as "the means to providing the basic necessities of life... to meet our needs today while enabling future generations to meet their needs" [2]. Conservation equals a commitment to sustainable practices. Certainly there is a common sense notion that reusing existing buildings is better than demolishing and replacing them. The fact is that reducing waste, rather than accepting and managing it, has become a critical priority. Reference [3] points out the essential coincidence between conservation and sustainability in the ' 3 Rs' i.e. reduce, reuse and recycle of nonrenewable resources [3]. Reference [4] defines the embodied energy as "the quantity of energy required by all activities associated with a production process" [4].Additionally, reference [5],in his speech at the National Trust annual conference, explains the term "embodied energy" as "the total expenditure of energy involved in the creation of the building and its constituent materials" [5]. Besides, Ashworth explains that historic buildings are often viewed as containers of stored value of embodied energy, and a sort of frozen employment [6]and [7]. Reference [8]gives an example: a heritage building with approximately 308,000 exterior bricks, each with an embodied energy value of 14,300 Thermal Units (BTU), represents 4.4 million BTUs of energy expended in the original construction of the building, or 1.3 million kilowatt hours of electricity [8]. Reference [9]points out that conservation and adaptive reuse cause much less destruction to our natural resources than new construction. Interestingly, about 85 percent of the total embodied energy in materials is used in their production and transportation [9]. Unmasking these costs can provide strong incentives for a transition to more sustainable energy use, less profligate use of new materials, and greater use of existing building stock [10](see figure 1).

Existence of heritage structure is a testament to their sustainability because they have remained useful spaces.

A building and its components is a major tenet of sustainable design. Heritage structures are also sustainable for the types of architectural elements they employ. Because most of these buildings were built before the advent of air-conditioning, they utilize the earth's natural energies, such as sunlight and wind. This consideration is crucial to "greening" a heritage building because the original materials have largely performed admirably over decades and even centuries. Removing the heritage fabric or damaging it to the point of necessitating its removal would thus create a less sustainable structure, even if the replacement was considered more efficient.

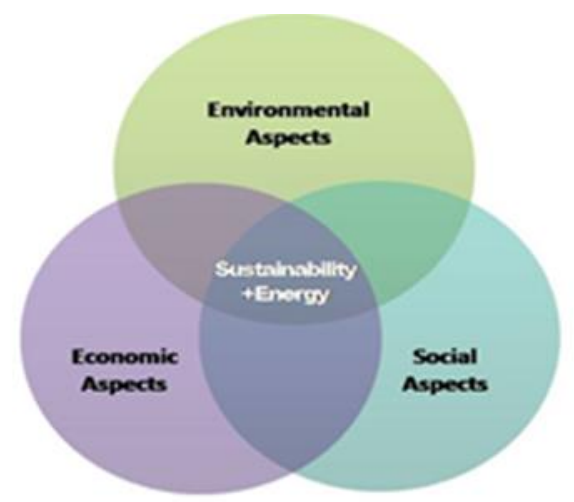

\section{Sustainability and Energy Diagram}

Energy is a major source of Environmental Stress

Energy is a key for macroeconomic growth

Energy is a prerequisite for social human needs Sustainability +Energy

Fig .1. Sustainability and Energy Diagram (Source: Author).

Reference [11] identifies the role buildings play from an energy usage perspective, and it is believed that the future energy adaptive qualities and design buildings will have to incorporate with their concepts [11]. It has been concluded that conservation of energy within buildings has an integral role in the effort to cut down on energy consumption. Furthermore, reference [12] recognizes the benefits associated with reusing heritage structures versus 
building new ones. He explains the benefits of intensifying the discussion to encompass environmental benefits, including the issue of embodied energy [12].

Moreover, the Advisory Council on Historic Preservation commissioned a study regarding energy conservation and heritage structures. The aim was to provide a tool for determining the energy value of heritage structures. The methodology related to embodied energy used by the Advisory Council for Historic Preservation (ACHP) measured the embodied energy of materials and construction for existing, rehabilitated and new construction. It also measured the demolition energy for existing buildings; including the energy to demolish, load and drag away building materials [13]. Besides, Carter overviews the importance of the study produced by the ACHP, Assessing the Energy Conservation Benefits of Historic Preservation: Methods and Examples, and affirms that it must extremely influence the conservation movement and perhaps transform the way effects on the built environment are evaluated [14].

\section{B. Resource Conservation and Adaptive Reuse}

In 1993, the U.S. Green Building Council was established with a mission to support sustainability in the industry of building and construction. Additionally, the U.S. Green Building Council delivered the green rating system, LEED. LEED is therefore defined as: "The most widely recognized and widely used green building program across the globe. LEED is certifying 1.6 million square feet of building space each day in more than 130 countries. LEED is a certification program for buildings, homes and communities that helps guide the design, construction, operations and maintenance. Today, nearly 50,000 projects are currently participating in LEED, comprising more than 8.9 billion square feet of construction space." [15]. LEED has provided the basis for the building business to begin designing with sustainable incentives. This has raised the question: How would heritage structures be compatible in a world with limited resources?

Responsiveness of the need to decrease greenhouse gas emissions has transferred the sustainability initiative from an energy crisis to a climate of alleviation. Over the last years, buildings have continually been noticed as the largest energy use sector over transportation and industry. As energy use by buildings continues to be a growing anxiety, the conservation community can gain traction on the dispute of heritage buildings adaptive reuse. Reference [16] has declared that the greenest building is the one that is already built [16]. Reference [16] viewpoint has become the framework for a dispute for many to defend the value of energy embodied in heritage buildings.

Fig. 13 shows a photograph of the complete experimental setup. In this figure, the host PC including the ISPACE controller, which is used to control and monitor the system variables by using the connector pins interface, is shown. Also, the power and interface circuits of the laboratory prototype of the proposed multi-phase MC are shown.

Reference [17], the former President of the Athena Sustainable Materials Institute, discusses the environmental gains in renovation versus new constructions. This is considered the benchmarking approach of comparing demolition versus new construction and estimating the environmental impacts that are avoided by saving an existing building [17]. Reference [17] looks at two scenarios, the first is the minimum avoided impact case, which entails saving only the structural system of a building, while the rest is demolished or replaced. The second scenario is the maximum avoided impact case, which involves saving the wrapping as well as the structure. A well known researcher concluded that life cycle assessment should be used for renovation projects as a decision support methodology, if the appropriate data and tools are accessible [17].

The Athena Sustainable Materials Institute has examined the life cycle analysis, and whole building energy simulation, in evaluating the material and operational environmental effects of rehabilitating an existing building compared to new construction [18]. Furthermore, renewed heritage buildings can function comparably to new buildings using common environmental measures such as energy power and global warming contributions [19]. Finally, in 2012, the Preservation Green Lab has released its prominent study results which conclude that building reuse constantly offers environmental savings over demolition and new construction. Moreover, it can take between 10 and 80 years for a new, energyefficient building to surmount, through more efficient operations, the negative climate change impacts that were formed during the construction process [20]. 


\section{Embodied Energy and the ACHP Model}

The Advisory Council for Historic Preservation in their report, defines embodied energy as the energy which is measured in fossil fuels, and that was consumed to make any product, bring it to market, put it to use, and then to dispose of the product at the end of its useful life [13]. The First and Second Law of Thermodynamics provide the basis for exploring embodied energy in resources. Therefore, the quality of a resource will determine and influence its utility and value within a system, by raising the quality of a resource, and it will enforce its own set of environmental demands. Stein displays this law through the life cycle of a brick [21]. The brick has the same amount of material as an equivalent chunk of clay in the ground. However, the brick in the brick wall has considerably more value than the unprocessed soil. In order for the clay in the ground to become a brick, it has to go through a number of processes including: extraction of the raw clay, transportation, crashing and separation of the clay, shaping, firing in the furnace, transportation to the job site and assembly in the wall [21]. As a result, the brick has higher environmental demands. In order to raise the quality of the clay to that of a brick, energy has been added. As the brick weathers or declines by natural processes, or when it is demolished, the resources and energy that have been added to the material will be vanished. Decline of materials and assemblies as a building witness the passage of time is a predictable consequence of the Second Law of Thermodynamics. Buildings begin deteriorating at the point of finishing construction, slowly at first, and then accelerating the pace of deterioration before slowing once again. Building owners slow deterioration rate by preventative maintenance, or compensate deterioration with repairs and replacements, incrementally increasing the embodied energy, ultimately approaching the original values.

In view of that, the Advisory Council on Historic Preservation has reached a model whichprovides another tool for determining the total worth of threatened properties, and, in specific cases, whether retention and continued use are in the public interest. The Advisory Council of Historic Preservation has developed tools for assessing the potential energy conservation value that preservation provides. The following are outlined tools [13]. Firstly, the embodied energy of materials and construction for existing, rehabilitated, and new construction is the amount of energy required to process and put materials of construction in place. Embodied energy increases with the amount of processing and is not recoverable.

Secondly, demolition energy for existing buildings is the amount of energy required to raze, load, and haul away building construction materials. The annual operational energy for existing, rehabilitated and new construction is the amount of energy required to operate the facility where the operational energy depends upon climate; occupancy characteristics; and physical design of the building [13].

The methodology of the mentioned report looks at embodied energy of materials and construction for existing, rehabilitated and new construction [13]. The embodied energy calculation includes the amount of energy to process and put materials of construction into place. The first model presented is the building concept model. The report states that "results are generally correct but not precise," [21] (Booz, 1979, p.19). This model states that embodied energy is measured by assessing the building type and gross square footage [23]. The concept model as a formula is expressed as:

Embodied Energy Investment $=$ \{Gross floor area of heritage building $x$ invested energy per square foot specific to the building type from Exhibit 1$\}$.

The second model is the building survey model, and it is considered to be the most useful [13]. Hence, embodied energy is determined using a rough survey of primary material quantities, and applying their relevant energy values.

An evaluation of the data inputs for the above methods is further investigated to identify the justification behind the embodied investment dispute. The variance for heritage structures may be noticeable because structures were originally built in varying centuries with varying building technologies that had utilized varying energy yields. Hence, it is important to recognize the basis and origins of the data and numeric quantities. The U.S. Department of Energy provides a study of patterns of embodied energy through diverse construction industries [23]. The embodied energy total includes the embodied energy of the materials plus the direct energy of construction used at the site. The breakdown of the forty-nine categories is: seventeen are new building; five are building maintenance, repair and alteration; and the remaining twenty-seven are non-building construction and repair. The Department of Energy report stresses that 70 percent of embodied energy in 
new construction is attributed to fabrication of basic construction and components; the remaining 30 percent is due to delivery and setting up, including direct fuel purchases, administration, and transportation of materials, furnishings and construction equipment [23].

The Advisory Council on Historic Preservation report has become an embedded dispute within the field as a link to the sustainability conservation. The ACHP report has laid the basis for quantifying the energy value of conserving heritage structures. The ACHP model was innovative at the time of its release. However, at what position does the industry respond to the new wave of energy efficiency and green building design solutions? The answer to this question may be evident within the Preservation Green Lab, National Trust for Historic Preservation's recent study [24]. To express what embodied energy is basically accounting for a formula which can be articulated starting with the original capital investment, minus the losses due to decline, plus the added investment while ownership is maintained, equals the residual current value of investment (see figure 2). Consequently, the embodied energy method does not account for predictable processes that occur to every building such as deterioration and maintenance, therefore not accounting for the true current capital value of the building.

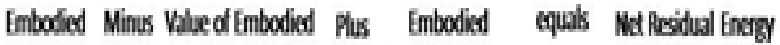

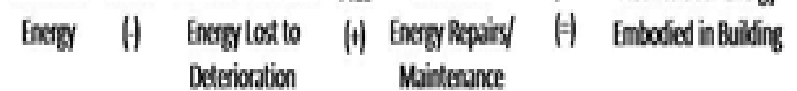

Fig .2. Formula to Express Embodied Energy (Source: Author based on Booz, 1979).

\section{Life Cycle Assessment of Heritage Structures}

While conservation is not the sole resolution to sustainability, it can be an integral part of it. The Whole Building Design Guide, in its 2012 article "Sustainable Historic Preservation," endorses the notion that "preserving a building is often called the ultimate recycling project" [25]. It goes on to detail intrinsic sustainable features within heritage structures such as sustainable sites, water efficiency, energy and atmosphere, on-site renewable energy, green power, materials and resources and indoor environmental quality [25]. The reality is that these features emphasize the similarities and common characteristics in sustainability goals and conservation.
The Whole Building Design Guide refers to Life Cycle Assessment (LCA) which is defined by the United States Environmental Protection Agency as a technique to assess the environmental aspects, and potential impacts associated with a product, process, or service by compiling an inventory of relevant energy and material inputs and environmental releases; evaluating the potential environmental impacts associated with identified inputs and releases, in addition to interpreting the results to help you make a more informed decision [26]. LCA is also appropriate to heritage conservation as it can be utilized to assess the environmental values and benefits associated with reusing a building. This approach to investigating existing structures shifts the focus from solely embodied energy, which makes up a fraction of an LCA, to a whole building approach, and brings to the front position a range of environmental values [17]. The LCA assessment tool would be used to compare rehabilitation and new construction, in addition to comparing various rehabilitation options.

Furthermore, the Greenest Building: Quantifying the Environmental Value of Building Reuse study has explored the environmental impact reduction when rehabilitated buildings are compared to demolition and new construction. This LCA framework enables the conservation industry to look at key variables such as building life span and the efficiency of operation energy that may affect the decision to reuse buildings in opposition to building a new one [20]. Three key findings from the study are: firstly, building reuse almost always yields fewer environmental impacts than new construction when comparing buildings of similar size and functionality; secondly, reuse of buildings with an average level of energy performance consistently offers immediate climate change impact reductions compared to more energy efficient new construction; and thirdly, materials matter i.e. the quantity and type of materials used in building renovation can reduce, or even negate, the benefits of reuse [20].

\section{E. Athena Sustainable Materials Institute and Life Cycle Assessment Measures}

Several attempts were made to build up spreadsheets calculating environmental impacts of heritage buildings retention. Spreadsheets were therefore developed into software [27]. In 2002, it was released under the name Environmental Impact Estimator (and is currently called the Athena Impact Estimator for Buildings). A second tool, the Athena EcoCalculator 
for Assemblies, was developed in 2007. The Athena Institute is still a reliable source providing software, research and valuable information in the form of life cycle assessments for the construction industry. Examining the environmental impacts that are avoided by recycling a building opposed to demolition amplifies the dispute for conservation. Accounting for the energy, in the future, closes the gap that exists between the energy that was spent at initial construction, and the energy added for a replacement building. Therefore, the life cycle assessment/avoided impacts model is in alignment with the sustainability goals. The method used was novel and exemplary in the response to provide the conservation field the tools.

\section{METHODOLOGY}

\section{A. Heritage Conservation and Energy Sustainability in the International Context}

Heritage preservation groups around the world have begun not only informing others about the role of conservation in sustainability, but also utilizing sustainable practices in their own preservation projects. The U.S National Park Service, which oversees the Secretary of the Interior's Standards, has released standards to provide general goals for preservation projects at the international level, as well as guidelines for specific aspects of heritage construction. In fact, within the Secretary of the Interior's Standards for Rehabilitation, there are "special requirements for energy efficiency" that fall into their guidelines [28].

In addition, the National Trust for Historic Preservation is a national, private non-profit organization in U.S. that seeks to "save historic places and revitalize America's communities." [24]. The National Trust has partnered with LEED, or Leadership in Energy and Environmental Design, for several of their preservation projects, showing their dedication to increasing efficiency and sustainability even further in historic structures [29]. The Trust utilizes LEED certifications because their standards focus largely on the reuse of materials and resources in any construction project, whether it is a new or existing building. The National Trust has taken on even more involvement to partner with several U.S. national groups to create the Sustainable Preservation Coalition, which has made the goal of meeting with the U.S Green Building Council to improve LEED standards. The coalition's goal is to improve certain aspects of the LEED certification system, primarily because the current versions that "overlook the impact of projects of cultural value, do not effectively consider the performance....and embodied energy of historic materials and assemblies; and are overly focused on current or future technologies, neglecting the advantages of many traditional building practices." [29]. A heritage construction is inherently sustainable because it is extremely durable and often utilizes natural energies, and LEED standards should reflect this reality. However, even though there are many ways for the LEED certification process to improve, it is still possible for heritage buildings to be LEED certified, or even gain higher recognition in silver, gold or platinum LEED ratings.

Furthermore, English Heritage, officially known as the Historic Buildings and Monuments Commission of England, most recent efforts towards sustainability have culminated in a document aptly titled "Building Regulations and Historic Buildings: Balancing the needs for energy conservation with those of building conservation." [30]. The guide is meant to be an application of the country's regulation, which deals with energy conservation in new, existing, and heritage properties in order to reduce $\mathrm{CO} 2$ emissions and protect the building from negative impacts related to irreversibility.

\section{B. Energy Sustainability of Heritage Buildings: The Egyptian Status Quo}

The site of the Egyptian Ministry of Electricity and Renewable Energy was explored to look into Egyptian efforts towards energy sustainability of heritage buildings. Unfortunately, no information was available regarding this issue [31]. Since Egypt has been lacking a national program for this subject, it therefore has much to learn from efforts investigated abroad. This is the reason for investigating international literature and applying its experiences in this research. The Egyptian government and Egyptian governorates should coordinate to better inform the public about energy sustainability guidelines and their implementation benefits for heritage structures.

\section{Heritage Reuse in Alexandria, Egypt}

The practice of rehabilitating old buildings to extend their use, or recycling them for a new purpose is a well- established practice in many parts of the world. Generally speaking, the stock of potential reusable 
buildings in Alexandria is in Sharq district, in addition to the central urban area district (see figure 3). One can point out that Alexandria has maintained its downtown with architectural continuity to a certain extent. Likewise, there is a vast number of buildings in Alexandria that are candidates for continued adaptive reuse; thus adding up to those in the city centre. Some are outstanding examples of architecture and craftsmanship.

\section{Case Study Selection}

There is a tremendous impact to the environment when we construct something new, so avoiding new construction may be the most eco-conscious approach to our environment." [27]. Consequently, several heritage buildings were examined to select the case study taking into consideration accessibility to available needed information. The selected case study is a house which lies at Sharq district in Alexandria. It is registered as a villa no. 891 within Alexandria Heritage Report (see figure 4).

It lies at 24KafrAbdou Street in Alexandria [32] (Alexandria Heritage Report, 2007, Map no. 17).

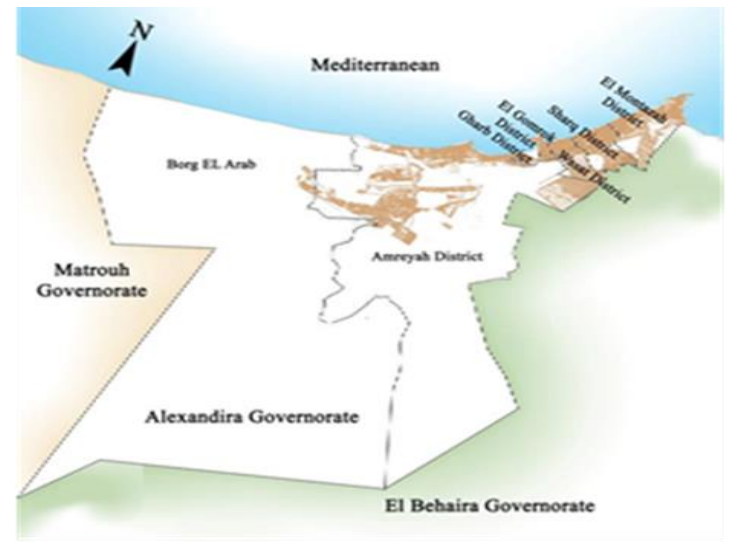

Fig .3. Alexandria Districts, with Sharq District

It is one of 463 listed buildings in Sharq district. It is categorized as important at the local level, the Architectural style is the English style. This style refers to buildings created under English influence or by English architects in parts of the world other than Britain, particularly in the later British colonies and Empire. The house has utilized the whites of splashes in the façade and windows of wood. The building roof is formed of wood and brick veneers. The height of the ground floor is 4 meters and the height of first and second floors are 3.5 meters.

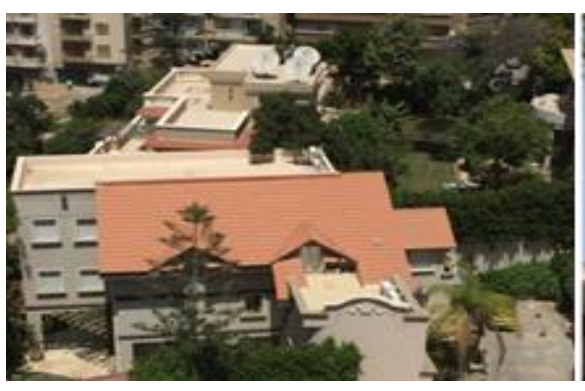

Fig .4.KafrAbdou villa (Source: author.) From Left: Arial Photo for villa in 2016.

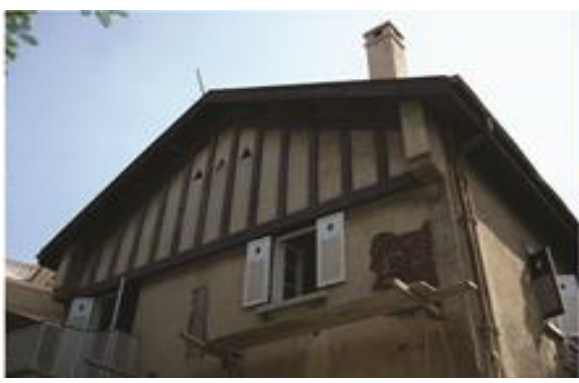

Middle: Villa before Rehabilitation.

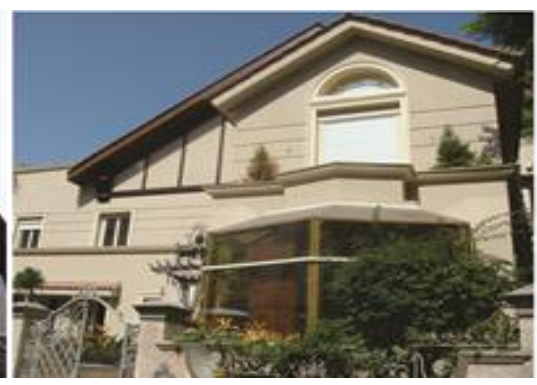

Right: Villa after Rehabilitation
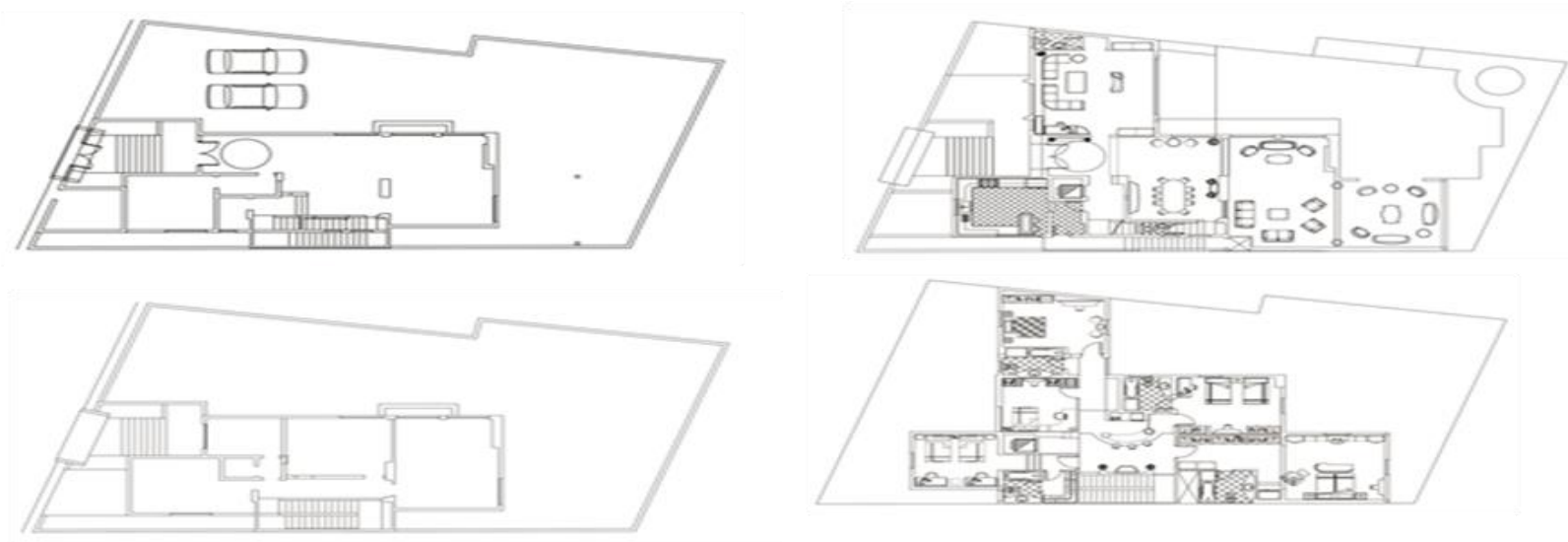

Fig .5.KafrAbdou villa (Source: Rehabilitation project consultant)

Up Left: Ground floor plan before rehabilitation

Down left: First floor plan before rehabilitation

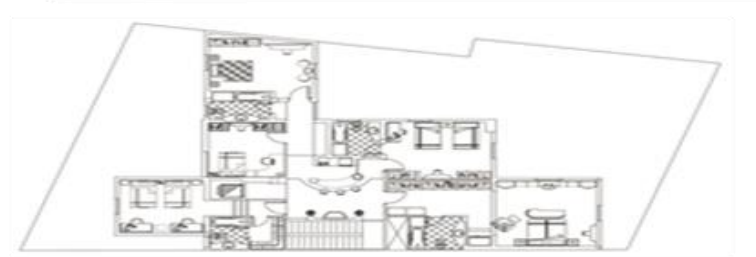

Up Right: Ground floor plan after rehabilitation Down Right: First floor plan after rehabilitation 


\section{- Case Study Original Form}

The house consists initially of a building with an area of 175 square meters per floor (2 floors $=3767$ sq. ft.) within a whole land parcel area of 470 square meters. The house originally composed of two floors only. The ground floor included the reception and a kitchen. The upper floor comprised 4 bedrooms and a living room.

\section{- Current Form after Development}

During the rehabilitation process, a mass of a 45 square meters area was added to both ground and first floors. An additional staircase was added leading to the second floor to meet the needs of the owner and access the second additional floor. An elevator was added as well. An additional basement of 90 square meters was supplemented below the building to accommodate four car parking spaces. The ground floor still comprises The second newly added floor is totally furnished and equipped as a private flat for the owner's son. It currently consists of three bedrooms, a living room and a kitchen.

- Building structure and details

The Structural system is Skeleton (i.e. beams and columns). Research focus is on material quantities of the original building to be able to calculate its contained energy. The original structure of the building includes 123 cubic meters of reinforced concrete columns and beams. The house foundation consists of additional 170 cubic meters. The foundation also includes 170 square meters of plain concrete.

\section{- Openings}

The house includes 12 windows openings of three different surface areas which comprise about 32 square meters.

- Brick exterior and interior walls

The total quantity of originally kept internal and external bricks is about 70 cubic meters of bricks $(70 * 35=2450 \mathrm{cf})$.

\section{- Wood Works}

Wood flooring of Swedish wood, and wood parquet totals 245 square meters (using 2inch thickness * 4inch width * 2450 length $=1633$ BF) are successfully kept.

- Asphalt pavement

Asphalt street outside is kept and it comprises 108 square meters of asphalt.

- Iron Works

Several iron works were kept such as iron doors and fences which have a quantity of 16 square meters $\left(16^{*} 300^{\star} 2.2=10560 \mathrm{lb}\right)$.

- Nonferrous Products

These materials may include mortar, sand beneath wood installations 22 tons approximately $(22 * 1000 * 2.2=48400 \mathrm{lb}$. $)$

- Infrastructure Works

All electric connections and sanitary works have been completed to accommodate and comprise current owner requirements.

\section{E. Research Procedure and Results}

The data gathered from the site includes a basic site visit to assemble building information, building dimensions, detection of observable materials, and applicable material quantities. The current function is residential. Interior access was not permissible. Architectural Drawings including detailed plans dimensions before and after restoration, sections and elevations, were received from the consultant architect who achieved the rehabilitation process [33]

The survey level methodology for the embodied energy analysis (ACHP) was applied for this case study. The survey method calculator is accessed through [22] www.thegreenestbuilding.org website.

The survey method examines major material components of the structure, and calculates the embodied energy of each individual element for calculation [22] (thegreenestbuilding.org website) (Table 1). The data sets comprise extraction of raw material, manufacturing, transportation and physical construction (see figure 6). 
Several assumptions were necessary for structural materials that were not visible. The green building association generates British thermal unit (BTUs) results based on the square footage of materials used in original construction. For this reason, all dimensions were changed from available French Metric units used in Egypt to British Metric units to be able to apply the Greenest Building calculations per square footage.

\begin{tabular}{|c|c|c|c|c|c|}
\hline \multicolumn{6}{|c|}{ Energy Used in Construction } \\
\hline Residential - Single Fa & - & 3767 & sq. ft. & & \\
\hline \multicolumn{6}{|c|}{ Material Categony } \\
\hline \multicolumn{2}{|l|}{ Wood Products } & \multicolumn{2}{|c|}{ Brick } & \multicolumn{2}{|l|}{ Concrete } \\
\hline 1633 & BDFT & 2450 & cf & 16205 & cf \\
\hline 14697000 & BTU & 980000000 & BTU & 1555680000 & BTU \\
\hline \multicolumn{2}{|l|}{ Paint } & \multicolumn{2}{|c|}{ Glass: windows } & \multicolumn{2}{|l|}{ Glass: plate } \\
\hline quantity (450 sf/gal.) & sq. $\mathrm{ft}$. & 344 & sq. $\mathrm{ft}$. & & sq. $\mathrm{ft}$ \\
\hline $\mathbf{o}$ & BTU & 5160000 & BTU & $\mathbf{o}$ & BTU \\
\hline \multicolumn{2}{|l|}{ Asphalt } & \multicolumn{2}{|c|}{ Iron \& Steel } & \multicolumn{2}{|c|}{ Non-Ferrous Products } \\
\hline 1162 & sq. $\mathrm{ft}$. & 10560 & lbs. & 48400 & Ibs. \\
\hline 2324000 & BTU & 264000000 & BTU & 4598000000 & BTU \\
\hline \multicolumn{2}{|l|}{ Calculate Clear } & 10726835 & \multicolumn{3}{|c|}{ MBTU Embodied Energy Investment* } \\
\hline
\end{tabular}

Fig.6. Survey method of energy calculations used in construction.[22] (Application Template :www.thegreenestbuilding.org).

The results from the survey method yield 10726835 MBTU Embodied Energy Investment. The result from calculations is of $10,726,835$ BTUs put into the Environmental Protection Agency's Greenhouse Gas Equivalencies Calculator 10,726,835 BTUs is equivalent to 770.3 metric tons of $\mathrm{CO} 2$ or $\mathrm{CO} 2$ equivalent. To humanize these results further: that is equivalent to the $\mathrm{CO} 2$ emissions from the energy use of 42.6 equivalent area homes for one year. This number is relevant when comparing it to the results from the LCA approach.

Limitations related with the embodied energy approach to quantifying value in heritage structures are first the handling. While the embodied energy calculator is accessible for free via the Internet, it is not a downloadable interactive document. An extra paper and pencil calculation to get BTUs is necessary. Time intensity for this approach is low. For the gross square footage calculation, it took approximately two hours to perform take offs of existing plans.

Besides, Athena EcoCalculator is a structured excel spreadsheet workbook, with tabs for various construction assemblies on each; individual worksheet with specific assembly information is included. All life cycle stages are taken into account: resource extraction and processing; product manufacturing; onsite construction of assemblies; all related transportation; maintenance and replacement cycles over an assumed building service life of 60 years; and the demolition and transportation of non-metal materials to landfill [27] (Athena Ecocalculator website).
Designed to be readily-applied, the EcoCalculator template can be used without outside consulting or help of any specialty, and the results are considered to be reasonable approximations as opposed to accurate estimates. The use of the Athena EcoCalculator is to estimate embodied environmental impacts, and global warming potential measured in terms of $\mathrm{CO} 2$ equivalence. Estimated avoided impacts associated with demolition of the existing building and construction of new buildings of essentially the same size is designed to serve the functions currently being utilized by the renewed buildings.

Hence, the EcoCalculator provides results for seven indicators of climate change impacts the classification of those seven impact categories are fossil fuel consumption (MJ), global warming potential (GWP) in tones $\mathrm{CO} 2$ e.g., acidification potential, human health criteria, eutrophication potential, ozone depletion potential and smog potential. These impact measures can be assessed to determine which assemblies provide the lowest negative impact by entering the square footage of materials into different assemblies. The summary of the results from the EcoCalculator is accounted for across the eight climate change indicators (see figures 7, 8 and 9).

The total avoided impacts for global warming potential (GWP) were compiled and the inclusion of calculating the global warming potential for whole building demolition was added on as an avoided impact in case of the reuse of an existing building (see figure 7). The assembly groups are also represented by the percentage contribution from each assembly to the seven climate change indicators (see figure 9). 


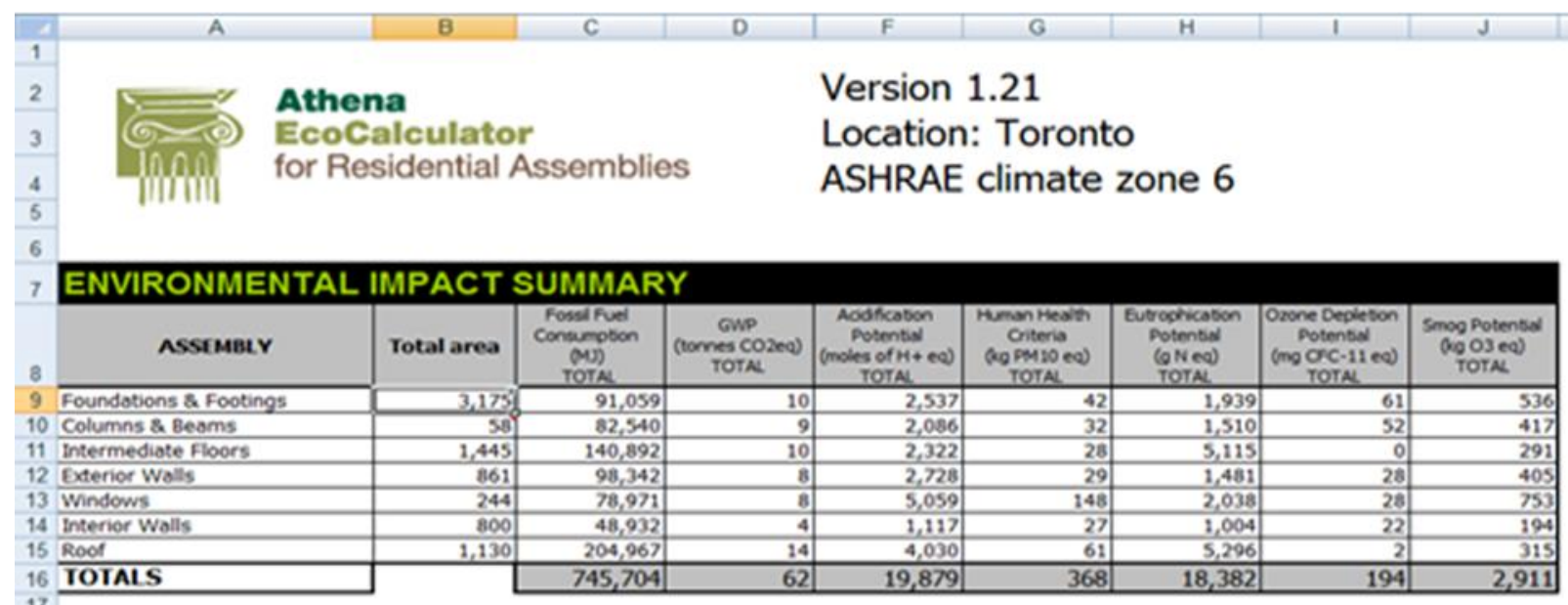

Fig .7. Athena EcoCalculator Results on Spreadsheet. (Application Template:www.athenasmi.org).
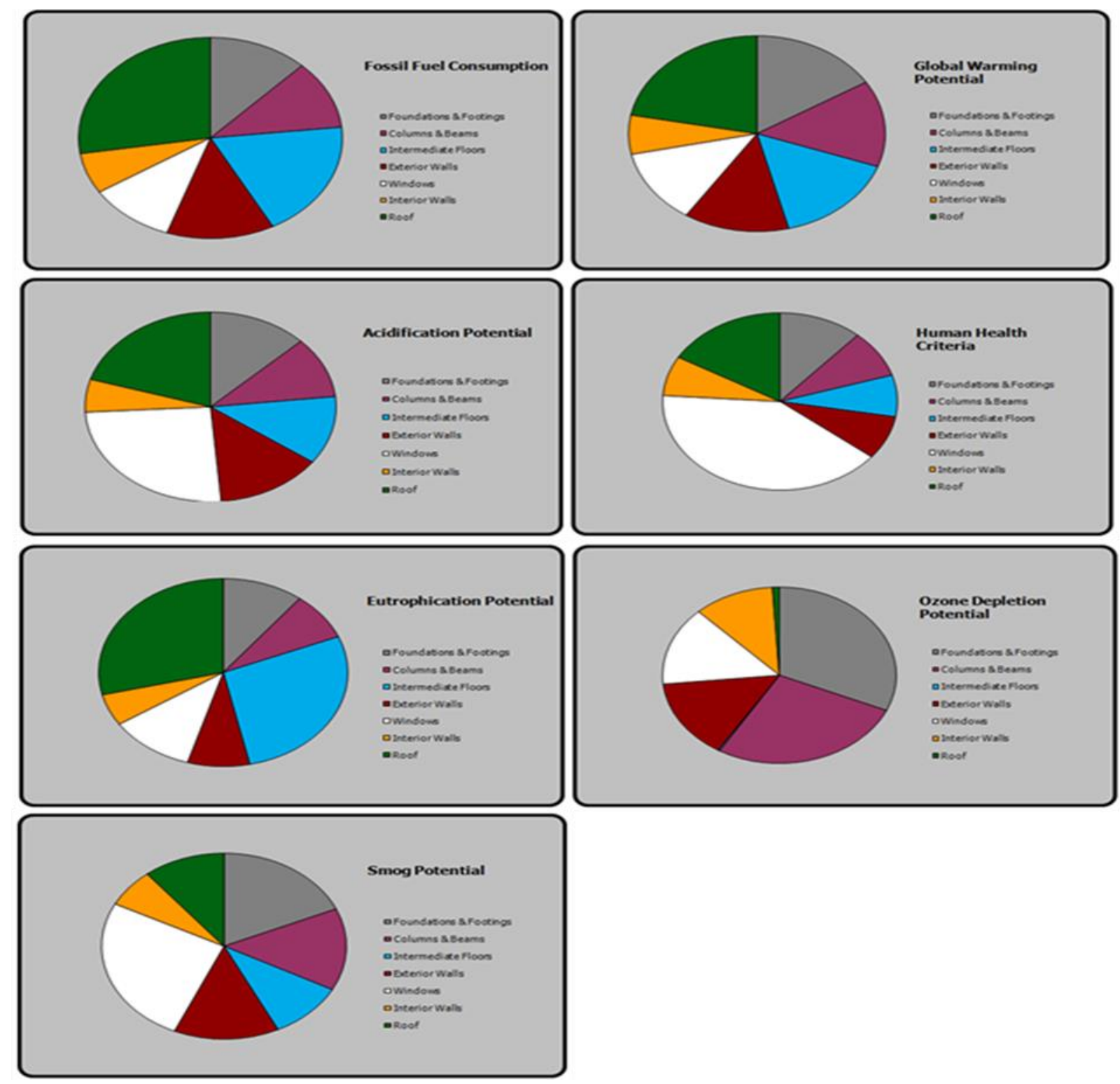

Fig.8. Athena EcoCalculator Results in the form of Pie charts (Application Template: www.athenasmi.org). 


\section{Percentages by assembly groups} (these results are shown in the pie charts below)

\begin{tabular}{|c|c|c|c|c|c|c|}
\hline $\begin{array}{l}\text { Fossil Fuel } \\
\text { Consumption }\end{array}$ & $\begin{array}{l}\text { Global } \\
\text { Warming } \\
\text { Potential }\end{array}$ & $\begin{array}{l}\text { Acidification } \\
\text { Potential }\end{array}$ & $\begin{array}{l}\text { Human } \\
\text { Health } \\
\text { Criteria }\end{array}$ & $\begin{array}{c}\text { Eutrophication } \\
\text { Potential }\end{array}$ & $\begin{array}{c}\text { Ozone } \\
\text { Depletion } \\
\text { Potential }\end{array}$ & $\begin{array}{l}\text { Smog } \\
\text { Potential }\end{array}$ \\
\hline $12 \%$ & $16 \%$ & $13 \%$ & $11 \%$ & $11 \%$ & $32 \%$ & $18 \%$ \\
\hline $11 \%$ & $14 \%$ & $10 \%$ & $9 \%$ & $8 \%$ & $27 \%$ & $14 \%$ \\
\hline $19 \%$ & $16 \%$ & $12 \%$ & $8 \%$ & $28 \%$ & $0 \%$ & $10 \%$ \\
\hline $13 \%$ & $13 \%$ & $14 \%$ & $8 \%$ & $8 \%$ & $15 \%$ & $14 \%$ \\
\hline $11 \%$ & $12 \%$ & $25 \%$ & $40 \%$ & $11 \%$ & $14 \%$ & $26 \%$ \\
\hline $7 \%$ & $6 \%$ & $6 \%$ & $7 \%$ & $5 \%$ & $11 \%$ & $7 \%$ \\
\hline $27 \%$ & $22 \%$ & $20 \%$ & $17 \%$ & $29 \%$ & $1 \%$ & $11 \%$ \\
\hline
\end{tabular}

Fig.9. .Athena EcoCalculator Percentages on Spreadsheet. (Application Template: www.athenasmi.org).

Out of the eight climate change indicators, global warming potential is the indicator that can be translated into a carbon dioxide equivalent. Global warming potential (GWP), as defined by the Environmental Protection Agency, was developed to compare the ability of each greenhouse gas to catch heat in the atmosphere relative to another gas. The definition of a GWP for a particular greenhouse gas is the ratio of heat trapped by one unit mass to the greenhouse gas to that of one unit mass CO2 over a specified time period [26] (U.S. environmental Protection Agency website). The avoided GWP impact of case study house is equivalent to emissions from the electricity use of 16equivalent area homes for one year, or $\mathrm{CO} 2$ emissions from the energy use of equivalent area of 5.2 homes for one year.

As it is the case with any model, there are particular limitations in the system. When calculating the square footage for the Exterior Walls assembly, there is a built-in 20 percent window to wall ratio. The model automatically accounts for the 20 percent ratio. Time and user building construction knowledge is the second limitation. While this template is accessible, it does require the user to have some basic architectural building construction knowledge to choose appropriate building assemblies.

\section{DISCUSSION}

Historically, the conservation field has relied on the embodied energy outputs of BTUs when discussing the energy capital in existing structures [13]. However, with the development of the LCA/avoided impacts approach, outputs in the form of GWP or carbon dioxide equivalent emissions can be utilized to still maintain the gallons of gas comparison [26]. The environmental avoided impacts model provides a currency that is interdisciplinary. The environmental avoided impact incorporates not just emissions from $\mathrm{CO} 2$, but also human health, acidification, water, etc... [27].

This case study identifies and applies two ways to approach quantifying the energy capital in heritage structures. Both provide quantitative results, but with different units of measurements. The EcoCalculator Life Cycle Assessment measured the energy capital in terms of eight climate change indicators, and focused on global warming potential [27], while the Advisory Council for Historic Preservation embodied energy ACHP model measured the energy capital in BTUs. Both approaches have developed results that represent a currency that has the potential to be communicable across the sustainability community. When measuring embodied energy, capital energy is viewed retrospectively. We value a building currently in terms of energy that has been expended historically, not taking into account that a building declines over the years. The LCA/avoided environmental impacts approach looks at what total replacement with a comparable new building would require and accounts for the building declining over the years.

The role that heritage conservation plays within sustainability and the goal to reduce greenhouse gas emissions is already on its way to adapting to modern sustainability goals and policies. Examining the resulting unit of measurement indicates the embodied energy model, and produces results that are measured in BTUs, and they are commonly translated to gallons of gas. The life cycle 
assessment/avoided impacts model produces results in a metric of $\mathrm{CO} 2$ and GWP. In terms of the conservation field utilizing a common currency to communicate with experts driving sustainability the life cycle assessment/avoided impacts model provides these communicable measurements.

\section{CONCLUSION}

The role of the conservation field within energy sustainability will continue to expand and adjust since sustainable strategies and goals are continually developing. This research has highlighted the importance of the conservation field to stay side by side with the saved energy that is associated with sustainability. It is important for the conservation field to approach the ability to employ environmental avoided impact methods when discussing and assessing heritage structures.

The core aim of sustainability is to safeguard the eco-system for future generations. Conservation professionals should adapt to this role, as they have taken on the role of safeguarding structures, landscapes and cultures for years. The ability to reinforce the relationship between conservation, sustainability and energy should be the responsibility of the conservation field. Communicating in a common energy value and avoiding work in a silo will allow professionals to be successful at the reuse of heritage structures.

With trained professionals, heritage buildings can be better protected during retrofits, as well as becoming more efficient with less impact on the environment over time. With this understanding of the broader movement for sustainability and preservation internationally, we can begin to focus on and support such initiatives to be performed in Egypt.

\section{ACKNOWLEDGEMENT}

The researcher would like to recognize the support and provision of valuable information and architectural drawings provided by architect/ Hesham Shaker- Rehabilitation-project consultant. Thanks are due to Dr. Mohamed S.SolimanDepartment of Computer Engineering- Pharos University for his technical assistance with the applied software. The researcher also wishes to acknowledge the effort undertaken by Dr. Hebatallah Hassan- Pharos University in editing this article.

\section{REFERENCES}

[1] United States Energy Information Administration. "Annual Energy Review 2011." September 2012

Available at http://www.eia.gov/totalenergy/data/annual/pd f/aer.pdf. (Accessed 02 May, 2016).

[2] United Nations, The Rio Declaration on Environment and Development 1992, United Nations Conference on environment and Development, Rio de Janiero, Brazil. Reprinted in Sustainable Development Reader edited by Stephen M. Wheeler and Timothy Beatley. New York: Routledge, 2004.

[3] D. Rodwell, Conservation and Sustainability in Historic Cities, U.K.: Blackwell publishing Ltd, 2007.

[4] Treloar, Extracting Embodied Energy Paths from Input-Output Tables: Towards an InputOutput-Based Hybrid Energy Analysis Method. Economic Systems Research,Taylor and Francis.Vol. 9(4), 1997, pp. 375-91.

[5] D. Rypkema and K. Wiehagen, Dollars and Sense of Historic Preservation. The Economic Benefits of Preserving Philadelphia's Past. Washington D.C.: National Trust for Historic Preservation, 2000.

[6] Ashworth, Conservation Designation and the Revaluation of Property: the risk of heritage innovation, International Journal of Heritage Studies, 8(1), 2002, pp. 9- 23.

[7] D. A. Elsorady, The economic value of heritage properties in Alexandria, Egypt, International Journal of Heritage Studies, Volume 20, Issue 2, 2014, pp. 107-122.

[8] M. Wishkoski, Historic Preservation Projects can be Green, 2006. Available at http://www.djc.com/news/en/11177209.html (Accessed 13 March, 2016).

[9] V. Bahl, Ethics of Adaptive Reuse. Architectural Week.No.240, 2005, B1.1-B1.2.

[10] C. Langston and L. Shen, Application of the Adaptive Reuse Potential Model in Hong Kong A Case Study of Lui Seng Shun, 
International Journal of Strategic Property Management, 11, 2007, pp. 193-207.

[11] C. Griffin and P. Jr., Energy Conservation in Buildings: Techniques for Economical Design, Washington, D.C.: The Construction Specifications Institute, Inc., 1974.

[12] M. Jackson, "Embodied Energy and Historic Preservation: A Needed Reassessment", Association for Preservation Technology36, no. 4, 2005, pp. 47-52.

Available at http://www.jstor.org/stable/4003163. (Accesse d March 4, 2016).

[13] A. Booz, and H. Booz, Assessing the Energy Conservation Benefits of Historic Preservation: Methods and Examples, U.S.: Advisory Council on Historic Preservation, 1979.

[14] Carter, "Assessing Energy Conservation Benefits: A Study" in New Energy Old Buildings,ed. National Trust for Historic Preservation, Washington, D.C.: Preservation Press, 1981.

[15] U.S. Green Building Council. "About USGBC." Available at http://new.usgbc.org/about.(Accessed January 10, 2016).

[16] C. Elefante, "The Greenest Building Is...One That Is Already Built," Forum Journal: The Journal of the National Trust for Historic Preservation 21, no. 4 (2007), pp. 26-37.

[17] W. Trusty, "Renovating Vs. Building New: The Environmental Merits." Canada: The Athena Institute, 2007.

[18] Athena Sustainable Materials Institute, A Life Cycle Assessment Study of Embodied Effects For Existing Historic Buildings, CA: Parks Canada, 2009.

[19] M. Lucuik, W. Trusty, A. Huffman and A. Prefasi, The Greenest Building Is the One That Is Never Built: A Life-Cycle Assessment Study of Embodied Effects for Historic Buildings, ASHRAE, Buildings $\mathrm{XI}$, Canada, 2010.
[20] Preservation Green Lab, The Greenest Building: Quantifying the Environmental Value of Building Reuse, Washington, D.C.: The National Trust for Historic Preservation, 2012.

[21] C. Stein, Greening Modernism, New York: W.W. Norton and Company, 2010.

[22] National Trust for Historic Preservation - The greenest Building website

Available at http://www.thegreenestbuilding.org (Accessed January 10, 2016).

[23] United States Department of Energy, 2010 Buildings Energy Data Book. Prepared for the Building Technologies Program Energy Efficiency and Renewable Energy by D\&R International, Ltd. Under contract to Pacific Northwest National Laboratory, March 2011.

[24] The National Trust for Historic Preservation, "About Us".

Available at http//www.preservationnation.org/about-us (Accessed February 2, 2016).

[25] Whole Building Design Guide."Sustainable Historic Preservation."WBDG Historic Preservation Subcommittee. Available at http://www.wbdg.org/resources/sustainable_h p.php.(Accessed January 10, 2016).

[26] United States Environmental Protection Agency. "Life Cycle Assessment (LCA)."Available at http://www.epa.gov/nrmrl/std/lca/lca.html.(Acc essed March 2, 2016).

[27] Athena Sustainable Materials Institute, Athena EcoCalculator, Available at http://www.athenasmi.org/our-softwaredata/ecocalculator/ (Accessed April 18, 2016).

[28] K. Weeks and A. Grimmer, The Secretary of the Interior's Standards for the treatment of Historic Properties with Guidelines for Preserving, Rehabilitating, Restoring and Reconstructing Historic Buildings, Washington D.C: U.S Department of the Interior, 1995, pp. 56-57. 
[29] B. Campagna, "How Changes to LEED Will Benefit Existing and Historic Buildings," Forum News, 15, 2008.

[30] English Heritage, "Who We Are", Available at http://www.englishheritage.org.uk/server/show/nav.1665.(Acces sed March 4, 2016).

[31] Egyptian Ministry of Electricity and Renewable Energy
Available

at http://www.moee.gov.eg(Accessed March 4, 2016).

[32] ALEX-MED, Alexandria Heritage Catalogue 2007. Alexandria: Bibliotheca Alexandrina, 2007.

[33] Interview with rehabilitation consultant, March 2016). 